\section{Conclusion}

Ikervis has been marketed as a dry eye product with less tolerance issues than other forms of topical ciclosporin (predominantly due to vehicle differences) and effective as a once daily dose (reducing instillation frequency and associated discomfort) [4]. In our study, Ikervis was tolerated in the majority of these DED patients with reasonable treatment duration (mean 11 months). However, local ocular irritation led to intolerance of treatment in a small number of patients (7.7\%). It has been suggested that concurrent use of topical steroids during the initiation of topical ciclosporin use can improve tolerance by reducing local ocular side effects [5]. This appeared to be the experience for most of our patients, but was not universal, reflecting the severity and complexity of DED. The SANSIKA and SICCANOVE studies suggested that initial ocular irritation decreased with longterm Ikervis use [2, $3,6,7]$. Our small study provides real-world experience data regarding the use, persistence and tolerability of topical Ikervis outside the controlled confines of these key clinical trials.

\section{Compliance with ethical standards}

Conflict of interest The authors declare that they have no conflict of interest.

\section{References}

1. Jones L, Downie LE, Korb D, Benitez-Del-Castillo JM, Dana R, Deng SX, et al. TFOS DEWS II management and therapy report. Ocul Surf. 2017;15:575-628.

2. Leonardi A, Van Setten G, Amrane M, Ismail D, Garrigue JS, Figueiredo FC, et al. Efficacy and safety of $0.1 \%$ cyclosporine A cationic emulsion in the treatment of severe dry eye disease: a multicenter randomized trial. Eur $\mathrm{J}$ Ophthalmol. 2016;26:287-96.

3. Baudouin C, Figueiredo FC, Messmer EM, Ismail D, Amrane M, Garrigue JS, et al. A randomized study of the efficacy and safety of $0.1 \%$ cyclosporine A cationic emulsion in treatment of moderate to severe dry eye. Eur J Ophthalmol. 2017;27:520-30.

4. Lallemand F, Daull P, Benita S, Buggage R, Garrigue JS. Successfully improving ocular drug delivery using the cationic nanoemulsion, novasorb. J Drug Deliv. 2012;604204:27.

5. Sheppard JD, Donnenfeld ED, Holland EJ, Slonim CB, Solomon R, Solomon KD, et al. Effect of loteprednol etabonate $0.5 \%$ on initiation of dry eye treatment with topical cyclosporine $0.05 \%$. Eye Contact Lens. 2014;40:289-96.

6. Leonardi A, Messmer EM, Labetoulle M, Amrane M, Garrigue JS, Ismail D, et al. Efficacy and safety of $0.1 \%$ ciclosporin A cationic emulsion in dry eye disease: a pooled analysis of twodoublemasked, randomised, vehicle-controlled phase III clinical studies. Br JOphthalmol. 2018 Mar 15. pii: bjophthalmol-2017-311801. https://doi.org/10.1136/bjophthalmol-2017-311801.

7. Baudouin C, de la Maza MS, Amrane M, Garrigue JS, Ismail $\mathrm{D}$, Figueiredo FC, et al. One-year efficacy and safety of $0.1 \%$ cyclosporine a cationic emulsion in the treatment of severe dry eye disease. Eur J Ophthalmol. 2017;27:678-85.

\title{
Unique presentation of congenital cataract concurrent with microcornea, microphthalmia plus posterior capsule defect in monozygotic twins caused by a novel GJA8 mutation
}

\author{
Hongfang Zhang ${ }^{1} \cdot$ Zhenji Chen $^{1} \cdot$ Kaiwen $\mathrm{He}^{1} \cdot$ Pingjun Chang ${ }^{1} \cdot$ Yinying Zhao ${ }^{1} \cdot$ Xiufeng Huang $^{1} \cdot{\mathrm{Jin} \mathrm{Li}^{1}}^{1}$ \\ Zibing Jin $\left(^{1}\right)^{1}$ Yun-e Zhao ${ }^{1}$
}

Received: 22 December 2017 / Revised: 15 July 2018 / Accepted: 5 October 2018 / Published online: 29 November 2018

(c) The Author(s) 2018. This article is published with open access

\footnotetext{
These authors contributed equally: Hongfang Zhang and Zhenji Chen

Zibing Jin

jinzb@mail.eye.ac.cn

$\triangle$ Yun-e Zhao

zyehzeye@126.com

1 The Eye Hospital of Wenzhou Medical University, School of Ophthalmology and Optometry, The State Key Laboratory of Ophthalmology, Optometry and Vision Science, 325027

Wenzhou, China
}

Congenital cataracts are the most common diseases which account for 10-30\% of blindness in children [1]. Multiple genetic mutations contribute to the progression of this genetically heterogeneous and complex disease. Among the reported causative congenital cataract mutations, approximately one quarter are connexin genes, including Connexin 46 which is encoded by GJA3 and Connexin 50 which is encoded by GJA8 [2].

In this study, we encountered four generations of a Chinese family with bilateral congenital cataracts at the Eye Hospital of Wenzhou Medical University. Among the four affected 
Fig. 1 Anterior segment photographs of the affected individuals

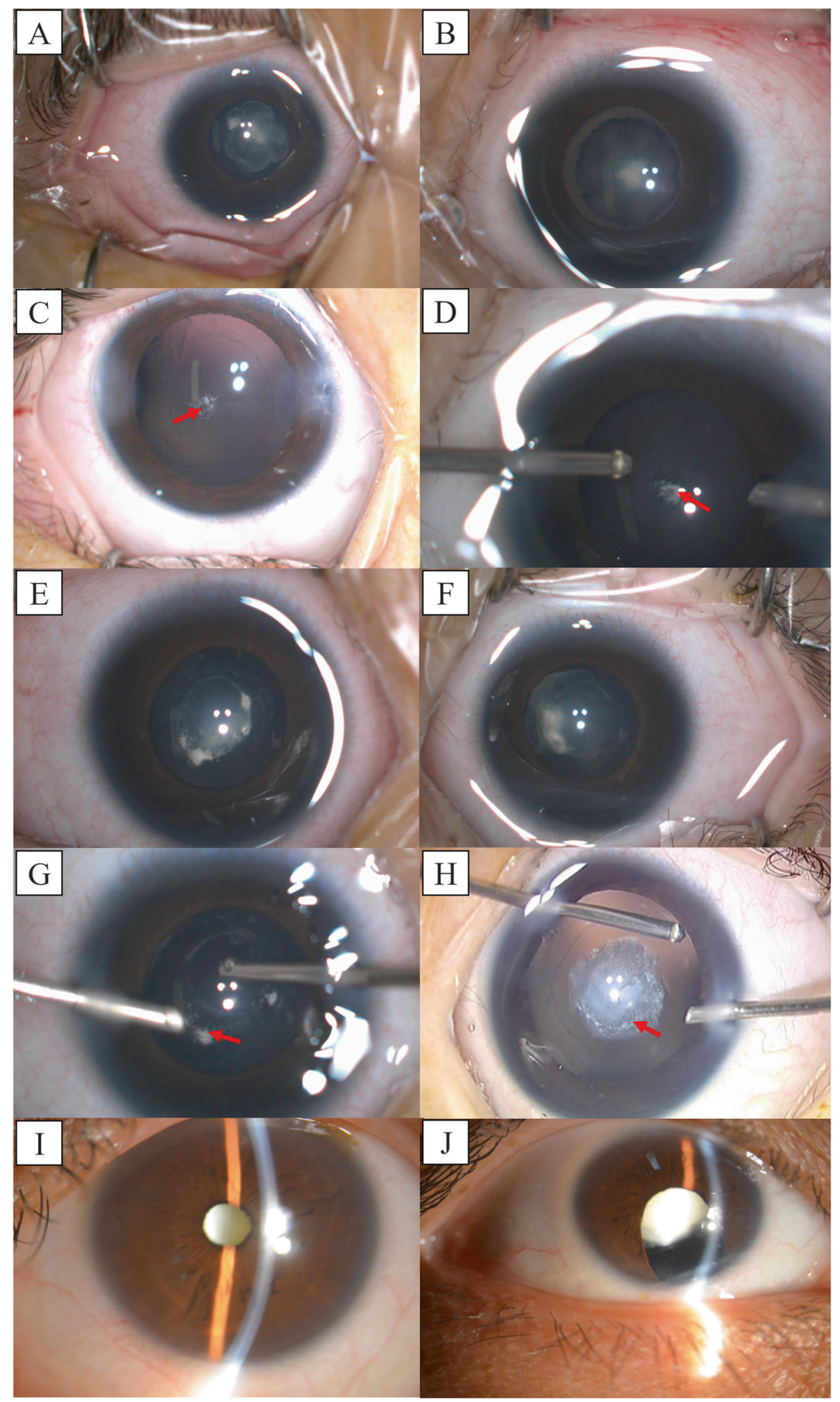


A

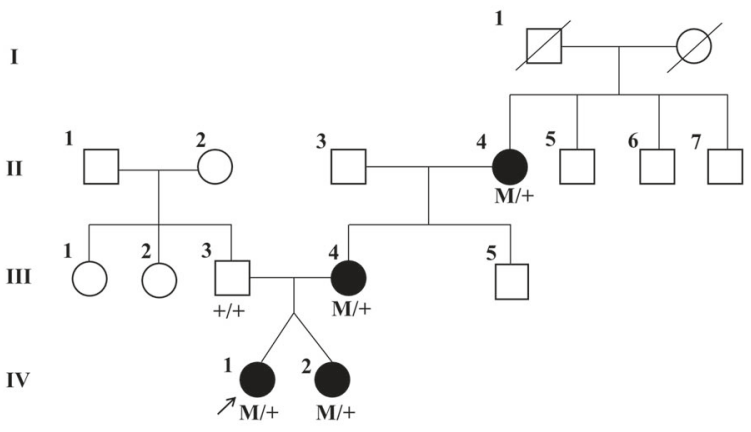

$\mathrm{C}$

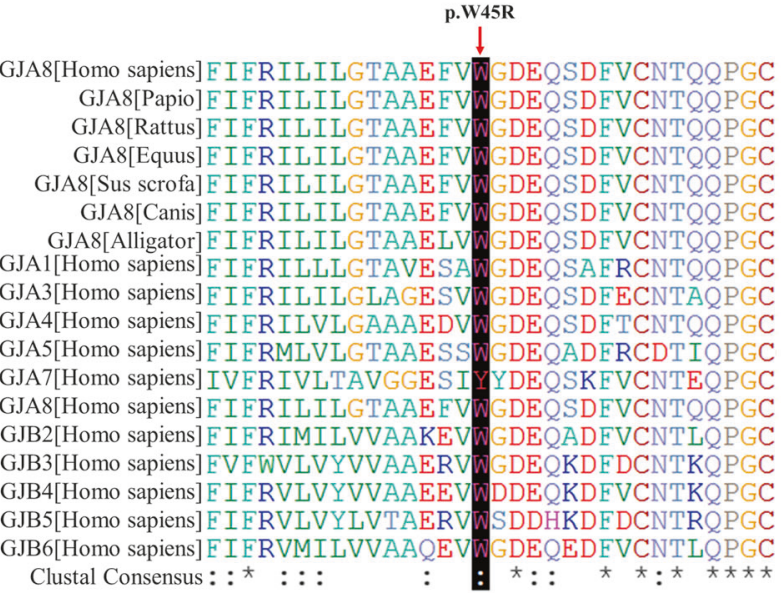

$\mathrm{B}$

GJA8

c. $133 T>C$

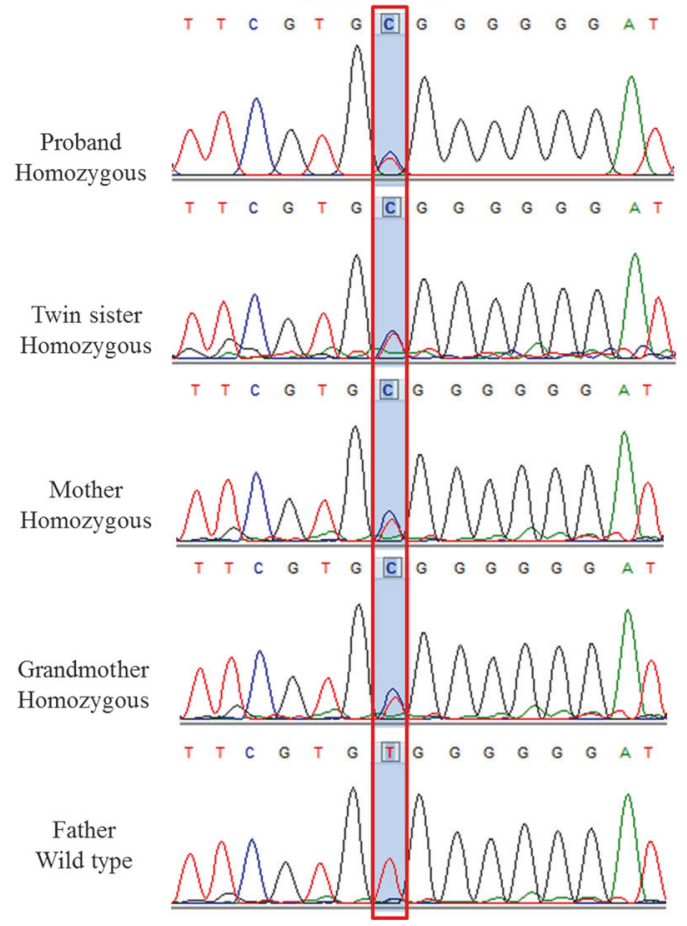

Fig. 2 A Pedigree of four generations of the family with autosomal dominant cataracts. B Chromatograms showing the DNA sequence analysis in the GJA8 mutation pedigree. C A multiple-sequence alignment of the amino-acid sequence in GJA8 from various species and isoforms

individuals in this family, two are twin sisters. The twins were diagnosed with bilateral congenital cataracts with microcornea, microphthalmia and posterior capsule defect (PCD). Photographs were obtained from a video of the surgery and confirmed the ophthalmologist's diagnosis. Anterior segment photographs of proband (Fig. 1A, B) and her twin sister (Fig. 1E, F) show nuclear cataracts. Their posterior capsule photographs (Fig. 1C, D, G, H) demonstrate posterior polar cataracts with posterior capsule defects. Photographs of their grandmother (Fig. 1I, J) show full cataracts.

To investigate the causative mutation in this family, we first performed whole exome sequencing on DNA from subject IV-1 (Fig. 2A) and identified a novel missense mutation, c. T133C, in GJA8. Sanger sequencing confirmed that the mutation co-segregated with all affected individuals and was not observed in the unaffected family member or in 100 unrelated controls (Fig. 2B). The mutation resulted in a missense amino-acid change, tryptophan to arginine, which was absent in dbSNP137, $1000 \mathrm{G}$, ESP6500 and ExAC databases. The arginine residue at position 45 is highly conserved across species and isoforms (Fig. 2C). Moreover, p. W45R is predicted to be pathogenic by SIFT (score 0.00 out of 1.00, "damaging"), Polyphen-2 (score 0.999 out of 1.000, "probably damaging") and Mutation Taster (score 0.00 out of
1.00, "damaging"). Based on the above evidences, we can determine that the novel mutation (c.133 T > C, p.W45R) in GJA8 is the pathogenic mutation in this family.

In conclusion, our study identifies a novel missense mutation in GJA8 in a Chinese family with congenital cataracts using WES, thereby expanding the existing spectrum of GJA8 mutations.

\section{Compliance with ethical standards}

Conflict of interest The authors declare that they have no conflict of interest.

Open Access This article is licensed under a Creative Commons Attribution 4.0 International License, which permits use, sharing, adaptation, distribution and reproduction in any medium or format, as long as you give appropriate credit to the original author(s) and the source, provide a link to the Creative Commons license, and indicate if changes were made. The images or other third party material in this article are included in the article's Creative Commons license, unless indicated otherwise in a credit line to the material. If material is not included in the article's Creative Commons license and your intended use is not permitted by statutory regulation or exceeds the permitted use, you will need to obtain permission directly from the copyright holder. To view a copy of this license, visit http://creativecommons. org/licenses/by/4.0/. 


\section{References}

1. Reddy MA, Francis PJ, Berry V, Bhattacharya SS, Moore AT. Molecular genetic basis of inherited cataract and associated phenotypes. Surv Ophthalmol. 2004;49:300-15.
2. Shiels A, Bennett T, Hejtmancik M, Fielding J. Cat-Map: putting cataract on the map. Mol Vision. 2010;16:2007-15.

\title{
Is post-operative perfluorocarbon liquid tamponade for macula-on giant retinal tear safer than silicone oil?
}

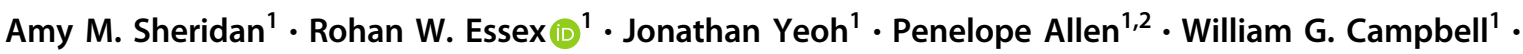 \\ Thomas L. Edwards (1) ${ }^{1,2}$
}

Received: 5 August 2018 / Revised: 25 September 2018 / Accepted: 26 September 2018 / Published online: 7 December 2018

(c) The Royal College of Ophthalmologists 2018

The incidence of unexplained central vision loss immediately following removal of silicone oil (ROSO) has been reported at between $3.3 \%$ [1] and 5.9\% [2], but may be considerably higher in certain retinal detachment subgroups. For example, the rate of ROSO maculopathy after macula-on giant retinal tear (GRT) repair was reported as high as $50 \%$ [1] in this journal, perhaps suggesting maculaon GRTs (Fig 1), or indeed any macula-on retinal detachment, are uniquely susceptible to ROSO maculopathy.

Perfluorocarbon heavy liquid (PFCL) as a short-term post-operative tamponade agent in GRT repair is a safe and effective alternative to silicone oil ( $\mathrm{SiO})$ or gas. This technique, first described by Bottoni [3] and subsequently by others [4-7], is used to manage all GRT detachments at the Royal Victorian Eye and Ear Hospital. PFCL remains in the eye for approximately 14 days, before exchange with fluid, air or gas. To investigate whether removal of short-term PFCL tamponade resulted in a lower rate of unexplained vision loss than ROSO in macula-on GRT detachments, we performed a consecutive retrospective review of all maculaon GRT repairs between 19 August 2007 and 12 December 2016. Best-corrected visual acuity (VA) was recorded at initial presentation, and 3 months following PFCL removal. The outcome of the procedure was determined at 3 months.

Thomas L. Edwards

thomas.edwards@unimelb.edu.au

Royal Victorian Eye and Ear Hospital, Melbourne, Australia

2 Centre for Eye Research Australia, Royal Victorian Eye and Ear Hospital, Melbourne, Australia
Statistical analysis was performed using a paired student's $t$ test assuming equal variance (alpha $=0.05$ ).

A total of 25 eyes in 24 patients (mean age 57 years; range 39-79 years) comprising 4 female patients (16.7\%) and 20 male patients $(83.3 \%)$ were included in the study cohort (Table 1). The mean (range) duration of PFCL tamponade was 14.6 days, (10-28 days) before removal and exchange either with 20 or $25 \%$ SF6 gas $(n=13,52 \%)$, air $(n=7$, $28 \%)$ or balanced salt solution $(n=5,20 \%)$. The mean baseline VA was 76 letters. The mean VA 3 months post-

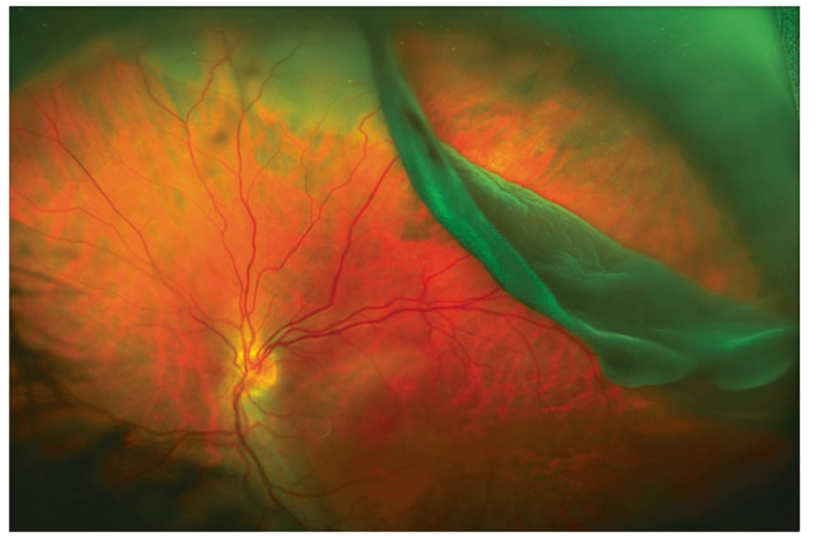

Fig. 1 Wide-field fundus photograph of the left eye showing a superotemporal giant retinal tear (GRT). A characteristic feature of this type of retinal detachment is posterior folding of the detached retina. Repositioning of the fold is facilitated by intra-operative perfluorocarbon liquid (PFCL) tamponade. Intra- or post-operative slippage can occur when the PFCL is exchanged for gas or, more rarely, silicone oil. An effective alternative is short-term post-operative tamponade with PFCL, which minimises the risk of retinal slippage 